\title{
Custo de oportunidade para a parte autora em processos judiciais eletrônicos: um estudo na procuradoria da União em Goiás
}

Michele Rílany Rodrigues Machado

Universidade Federal de Goiás

César Augusto Tibúrcio Silva

Universidade de Brasilia

Lúcio de Souza Machado

Universidade Federal de Goiás

A pesquisa teve como objetivo mensurar o custo de oportunidade para a parte autora em processos judiciais eletrônicos, quando da apresentação de cálculos pela Procuradoria da União em Goiás (PUGO). Foram analisados dados de 654 processos no período de janeiro de 2007 a dezembro de 2010, mediante abordagem quantitativa. O custo de oportunidade foi mensurado pela taxa de retorno, conforme Brealey e Meyers (2003) e Assaf Neto (2003). A taxa interna de retorno apurada para os processos em que a parte autora contestou os cálculos da PU-GO foi positiva em 3,23\%, o que evidenciou um ganho para a parte contestante. Os testes de média indicaram que os cálculos da PU-GO são significativamente superiores para as partes que concordaram com os cálculos. Quanto ao gênero da parte autora, tanto o valor recebido quanto o prazo de recebimento são superiores para as partes do gênero masculino.

Palavras-chave: custo de oportunidade; processos judiciais eletrônicos; parte autora; Procuradoria da União; Goiás.

El coste de oportunidad para el demandante en los expedientes judiciales electrónicos: estudio de la Procuraduría de la Unión de Goiás

La investigación tiene como objetivo cuantificar el coste de oportunidad de los demandantes en los expedientes judiciales electrónicos a partir de los cálculos efectuados por la Procuraduría de la Unión de Goiás (PU-GO). Mediante un enfoque de carácter cuantitativo se analizaron 654 procesos entre los meses de enero de 2007 y diciembre de 2010. El coste de oportunidad se midió por la tasa de rendimiento, según Brealey y Meyers (2003) y Assaf Neto (2003). La tasa interna de retorno computada

DOI: http://dx.doi.org/10.1590/0034-76121341

Artigo recebido em 25 out. 2012 e aceito em 8 maio 2014. 
en aquellos procesos en los que la parte demandante recurrió los cálculos de la PU-GO se incrementó positivamente en un 3,23\%, lo que supuso beneficios a favor de los recurrentes. Los tests de media señalan que los cálculos de la PU-GO son significativamente superiores cuando las partes acatan dichos cálculos. Cuando se trata de demandantes de género masculino se constatan índices más altos tanto en la cantidad a recibir como en el plazo para la recepción.

Palabras clave: coste de oportunidad; expedientes judiciales electrónicos; demandante; Procuraduría de la Unión; Goiás.

Opportunity cost for the plaintiff in electronic legal proceedings : a study in the Union attorney in Goias

The research aimed to measure the opportunity cost for to the plaintiff in electronics legal proceedings, considering the presentation of calculations by the Union Attorney in Goiás (PU-GO). We analyzed data from 654 legal proceedings from the period of January, 2007 to December, 2010, through a quantitative approach. The opportunity cost was measured by the rate of return, according to Brealey and Meyers (2003), and Assaf Neto (2003). The internal rate of return calculated for proceedings in which the plaintiff contested the calculations of PU-GO was positive in $3.23 \%$, showing a gain for the contesting party. The average tests indicated that the calculations of PU-GO are significantly higher for the parties who agreed with them. Concerning the gender of the plaintiff, both the value received and the deadline for receiving are higher for the parties of male gender.

KEYWORDs: opportunity cost; electronic legal proceedings; plaintiff; Union Attorney; Goiás.

\section{Introdução}

Integrante da estrutura da Advocacia-Geral da União (AGU), a Procuradoria da União no Estado de Goiás (PU-GO) é um órgão de execução, cuja competência é a representação judicial da PU-GO, no âmbito do Estado de Goiás, perante o Poder Judiciário da União e o Poder Judiciário Estadual (AGU, 2010).

A representação judicial é realizada pelos advogados da União, alocados em grupos de atuação, segundo o tema de cada processo. Dentro dos grupos de atuação, encontram-se os juizados especiais civis federais, nos quais estão as ações ajuizadas contra a PU-GO com valor da causa/pedido inferior a 60 salários mínimos, art. 3o da Lei ํㅜㅜ 10.259/2001.

Os juizados especiais federais foram criados pela Lei no 10.259 , em 12 de julho de 2001, com a finalidade de atender aos princípios constitucionais da celeridade na tramitação dos processos e eficiência. Ao buscar atendimento a esses princípios, em 19 de dezembro de 2006, foi publicada a Lei no 11.419 que instituiu o uso do meio eletrônico para tramitação de processos judiciais, doravante chamados de processos eletrônicos.

Tanto os processos eletrônicos quanto os processos físicos dos juizados especiais são submetidos aos mesmos ritos contidos no Código de Processo Civil, Lei no 5.869, de 11 de janeiro de 1973. Frisa-se que a Lei no 11.419, de 19 de dezembro de 2006, provocou alterações no Código de Processo Civil para adaptação da informatização dos processos judiciais. 
Esses ritos são como passos necessários até o reconhecimento, ou não, do direito pela justiça e o devido recebimento quando mensurável. Inicia-se pelo ajuizamento da ação, fase em que o autor reivindica aquilo que acredita ser um direito seu; em seguida, a parte ré contestará o pedido do autor e, então, o juiz declarará sua opinião quando reconhecerá, ou não, direitos da parte autora.

Ao existir o reconhecimento do direito, com o trânsito em julgado do processo, momento em que não cabem mais indagações da parte ré, passa-se à fase da liquidação da sentença. Essa é a etapa da quantificação monetária do direito, conforme arts. 475-A e 475-H do Código de Processo Civil. A apuração de valores pode ser calculada pelo autor, pelo réu, ou pela própria Justiça, por meio de sua Secretaria de Cálculos.

Quando da apresentação de cálculos pela PU-GO, o processo, após o reconhecimento do direito, segue o percurso definido como Caminho Tipo I, materializado na figura 1.

Figura 1

Caminho Tipo I

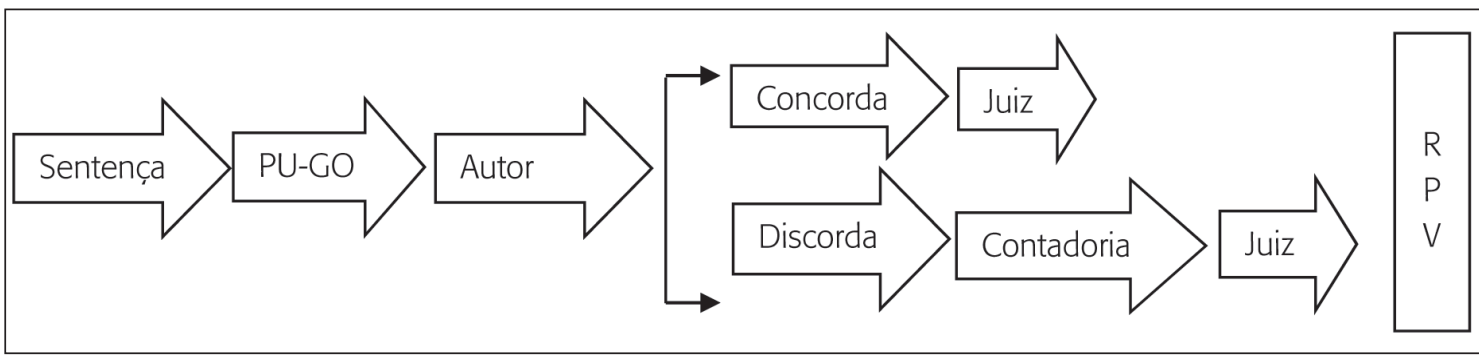

Fonte: Elaborada pelos autores.

No Caminho Tipo I, a parte autora, de posse dos cálculos apresentados pela PU-GO, deverá optar por concordar ou contestar os valores da PU-GO; o que gera, assim, um custo de oportunidade em função da escolha a ser realizada.

Ao aceitar os cálculos realizados pela PU-GO, o juiz determinará a emissão da Requisição de Pequeno Valor (RPV). Ao contestá-los, o processo será enviado à secretaria de cálculos da justiça, que elaborará novos cálculos e emitirá opinião sobre os da PU-GO.

O juiz poderá, nesse momento, decidir qual dos cálculos apresentados reflete melhor suas determinações, ou reenviar o processo à PU-GO, para que esta se manifeste sobre os cálculos da Secretaria, como forma de melhor subsídio para sua decisão.

Como se pode perceber na figura 1 , no Caminho Tipo I, a conclusão e o devido recebimento do direito decorrem do comportamento do autor. Ao contestar os cálculos, este trocará o recebimento de um fluxo de caixa presente por um fluxo de caixa futuro, que só ocorrerá após a participação da secretaria de cálculos da justiça e a decisão do juiz.

Em outras palavras, a opção do autor em não fazer a contestação pressupõe que o mesmo faz uma análise entre os dois fluxos de caixa, presente e futuro, para, então, tomar sua decisão ao ter como base o custo de oportunidade. 
O custo de oportunidade representa o valor que se deixou de ganhar por não se terem aplicado os recursos em outra alternativa. Esse conceito é utilizado sempre que existe uma situação de escolha entre várias alternativas de decisão (Nascimento, 1998).

Assim, a mensuração do custo de oportunidade para a parte autora de processos judiciais eletrônicos é relevante, pois essa informação a subsidiará em sua tomada de decisão, a de concordar ou não com os cálculos da PU-GO.

Diante do exposto, a pesquisa visa responder a seguinte indagação: qual o custo de oportunidade em processos judiciais eletrônicos, para a parte autora, quando a Procuradoria da União em Goiás (PU-GO) apresenta cálculos (caminho I)?

Dessa forma, a presente pesquisa tem como objetivo geral mensurar o custo de oportunidade do dinheiro em processos eletrônicos para a parte autora quando da apresentação de cálculos pela Procuradoria da União em Goiás (PU-GO).

Esta pesquisa se destaca por aplicar a conceituação de custo de oportunidade a processos judiciais eletrônicos, do ponto de vista da pessoa física, representando uma contribuição na análise do tema. Esse tipo de contribuição não foi encontrado nas pesquisas nacionais (Scarpel e Milioni, 2002; Figueiredo et al., 2006; Oliveira e Carvalho, 2007; Viana e Silveira, 2009) e internacionais (Keir e Keir, 1983; Lott, 1987; Lynk, 1990; e Bebchuk e Guzman,1996) que envolvem a temática de custo de oportunidade. Assim, uma limitação na realização deste estudo é a não comparabilidade com pesquisas similares, o que será melhor explorado na fundamentação teórica.

\section{Fundamentação teórica}

\subsection{Conceituação, histórico e origem da escola Law and economic e princípios de economia, segundo Richard Posner}

A análise econômica do direito, Law and economics, busca a sua compreensão, ao partir de pressupostos e valores econômicos, aplicáveis ao caso concreto pelo magistrado. Dessa forma, a racionalidade econômico-jurídica interage com o meio, de forma a determinar e influenciar a prática jurídica e o delineamento de novas linhas no ordenamento em geral; segundo novos padrões econômico-valorativos, quando da apreciação judicial de casos (Gonçalves e Stelzer, 2006).

A origem da escola Law and economic, direito e economia, segundo Parisi e Rowley (2005), foi com a publicação dos artigos A fragment on government (1776), seguido pelo Introduction to the principles of morals and legislation (1789), elaborados por Jeremy Bentham.

De acordo com Parisi e Rowley (2005), Bentham foi o primeiro estudioso a relacionar direito com economia. A descoberta fundamental de Bentham, em seu primeiro artigo, foi o princípio da maior felicidade; também conhecido como princípio da utilidade, qual seja: é a maior felicidade do maior número que é a medida do certo e errado. 
No segundo artigo, Bentham argumentou que a teoria e a prática da política e da lei poderiam ser reconstruídas por meio de seu primeiro princípio, o da maior felicidade.

Parisi e Rowel (2005) destacam que, na visão de pesquisadores modernos, o grande marco inicial da linha do direito e economia foi em 1960, ano que Ronald Coase publicou o artigo The problem of social cost.

Segundo Posner (2007), o início da nova Law and economic surgiu com os trabalhos publicados por Coase (1960), Calabresi (1961), e Becker (1968). Para Posner (2007), a lista de fundadores na nova Law and economic estaria incompleta sem citar Becker e suas contribuições, pela sua insistência na relevância da economia para uma variedade surpreendente de comportamento não mercado; além de contribuições específicas para análise econômica do crime, discriminação racial e casamento e divórcio.

Em seu artigo The problem of social cost, Coase (1960) apresentou o chamado teorema de Coase, no qual argumenta que, se duas partes estão negociando livremente, e na ausência de custos de transação, então, elas chegarão à economia ótima, a um consenso que satisfará as duas partes envolvidas na negociação.

Para Posner (2007), essa é a mais célebre aplicação do conceito de custo de oportunidade na análise econômica da lei. Além de seu teorema, Coase estabeleceu um trabalho para analisar a adjudicação do direito de propriedades e obrigações em termos econômicos (Posner, 2007).

Afora Coase, Beker e Calabresi, Richard Posner é citado por Parisi e Rowel (2005) como o mais importante estudioso da Law and economic desde a primeira publicação de seu livro Análise econômica da lei, sendo responsável pela forma que a Law and economic pós-coasiana tem voltado, tanto para dimensão normativa como positiva.

Posner (2007) relata que a economia é uma poderosa ferramenta para analisar uma vasta extensão de questões legais; contudo, a maioria dos advogados e estudantes de direito tem dificuldades de conectar os princípios econômicos aos problemas legais concretos, por acreditarem que ela está envolvida apenas com estudo matemático da inflação, desemprego, ciclos de negócios e outros fenômenos macroeconômicos distantes do sistema legal. Assim, em seu livro Economic analysis of law, Posner apresentou três princípios da economia para permitir o entendimento e a aplicação da economia ao direito.

O primeiro princípio, definido por Posner (2007), refere à relação inversa entre a alteração de preço e quantidade demandada (Lei da Demanda). O aumento no preço de um determinado produto resultará na redução na quantidade demandada desse produto, como, também, se a quantidade ofertada de um determinado produto cair, terá como efeito o aumento do preço desse produto.

O segundo princípio da economia é o custo de oportunidade, que, resumidamente, é o custo da segunda melhor alternativa abandonada, o qual será alvo de maior detalhamento no item 2.2 .

O terceiro princípio da economia é que os recursos tendem a girar em torno de seus usos mais valiosos se a troca voluntária — um mercado — é permitida. Posner (2007) afirma 
que, quando os recursos estão sendo usados onde seus valores são maiores, ou quando a realocação não aumenta seu valor, estes estão sendo empregados eficientemente.

\section{Custo de oportunidade}

Heymann e Bloom (1990) entendem que o tema custo de oportunidade pode ser visto como uma parte do estudo do comportamento humano ou como um elemento da teoria econômica relacionada com a tomada de decisão dentro de um ambiente ideal de mercado.

Para o comportamento humano, a tomada de decisão é derivada de um conjunto de aspectos diferentes. Já para a teoria econômica, segundo Heymann e Bloom (1990:1), "O que o tomador de decisão quer e deseja não pode ser satisfeito por causa do limite dos recursos econômicos, definido como escassez".

Em função da escassez, existe uma situação de escolha a ser realizada; dessa forma, a aceitação de uma alternativa irá excluir a aceitação de outras, e o abandono de uma alternativa, ou alternativas, representa o custo de oportunidade do tomador de decisão.

Em 1969, James Buchanan já descrevia o custo de oportunidade como a representação da avaliação das oportunidades sacrificadas. No mesmo sentido, Pereira e colaboradores (1990:3) afirmam que o custo de oportunidade "pressupõe alternativa viável e, portanto, existente para o consumidor ou para o empresário. Pressupõe, também, uma decisão efetiva sendo tomada e que, o sendo, acarreta o sacrifício/abandono de outra(s) que não foi(ram)".

Basso (2005) assevera que, se nenhum objeto avaliado ou atividade é escasso, todos os pedidos de todos os povos em todos os períodos podem ser satisfeitos; portanto, não existiria a necessidade de escolher entre as opções avaliadas separadamente, não existiria oportunidade ou alternativa perdida ou sacrificada. Assim, com a escassez nem todas as necessidades ou demandas podem ser satisfeitas; o que obriga a escolha da melhor alternativa disponível.

Observam-se pontos em comum nos conceitos apresentados por Buchanan (1969), Heymann e Bloom (1990), Pereira e colaboradores (1990) e Basso (2005), que são: a escolha de alternativas viáveis e o sacrifício das abandonadas, em que a melhor alternativa refutada se refere ao custo de oportunidade na tomada de decisão.

O conceito de custo de oportunidade é estudado de formas diferentes tanto na economia, finanças e contabilidade. Na economia, segundo Heymann e Bloom (1990), o conceito tem sido discutido por David Ricardo (1772-1823) e outros economistas nos anos anteriores a 1800, a fim de explicar os benefícios do comércio entre as nações com diferentes níveis de produtividade.

Para Assaf Neto (2003), no campo financeiro, o conceito de custo de oportunidade envolve os termos: decisão a ser tomada, alternativa abandonada e alternativa com riscos semelhantes. O autor conceitua o custo de oportunidade como o quanto uma pessoa ou empresa sacrificou de remuneração por ter tomado a decisão de aplicar seus recursos em determinado investimento alternativo, de riscos semelhantes. 
Para Beuren (1993), na literatura contábil sobre custo de oportunidade, observa-se que as abordagens em nível de contabilização vão de encontro ao conceito de custo de oportunidade, ao se distanciar do conceito original. As aplicações contábeis restringem-se a situações específicas (simplificadas), como juros sobre o capital próprio.

Nascimento (1998) evidencia a existência de um consenso entre as escolas econômicas, contábil e financeira: a dificuldade na mensuração do custo de oportunidade, em o conceito muitas vezes ser aplicado de forma restrita, ao desenvolver critérios para sua mensuração e contabilização que, na realidade, limitam sua aplicação na forma dos juros sobre o capital próprio consumido pela empresa em cada decisão de aplicação de recurso, o que é, entretanto, apenas uma forma específica de custo de oportunidade.

Como esta pesquisa visa mensurar o custo de oportunidade para a parte autora em processos eletrônicos, optou-se pela visão financeira do custo de oportunidade do capital. Nesta, como forma de mensuração desse custo, Brealey e Meyers (2003) apresentam a regra do valor presente líquido e a regra da taxa de retorno. Na primeira, o investidor decidirá sobre o projeto que apresentar um valor presente líquido positivo. Enquanto, na regra da taxa de retorno, o investimento ocorrerá enquanto o retorno sobre o investimento exceder a taxa de retorno dos investimentos equivalentes no mercado de capital.

Assaf Neto (2003) afirma que o custo de oportunidade não é um conceito absoluto, mas, apurado mediante a comparação do retorno esperado de uma decisão com o que seria obtido em uma melhor proposta de investimento, a alternativa rejeitada. Seguindo o pensamento de Assaf Neto (2003), de comparar o retorno esperado de uma decisão, para esta pesquisa, optou-se pelo cálculo da taxa de retorno interna para a mensuração do custo de oportunidade para a parte autora em processos judiciais eletrônicos ajuizados contra a Procuradoria da União em Goiás. A comparação da taxa de retorno interna com investimentos alternativos permitirá que a parte autora decida por concordar ou contestar os cálculos da PU-GO.

Existem diversos trabalhos empíricos nacionais sobre custo de oportunidade com aplicações em outras áreas. Oliveira e Carvalho (2007) tratam da aplicação do conceito de custo de oportunidade no spread bancário do Brasil nas operações de crédito. Viana e Silveira (2009) incluem o custo de oportunidade da terra na determinação do custo total, no uso do valor médio da poupança sobre o custo operacional. Figueiredo e colaboradores (2006), na pesquisa sobre criação de frangos de corte, usaram o conceito de custo de oportunidade; o que faz o custo médio ponderado de capital a proxy dessa variável.

Scarpel e Milioni (2002) fizeram uma modelagem da concessão de crédito, sendo considerada como custo de oportunidade a negativa de empréstimo para um cliente que efetuaria o pagamento. Os trabalhos citados mostram que o custo de oportunidade é estimado por uma proxy, como é o caso de Scarpel e Milioni (2002), Figueiredo e colaboradores (2006), e Viana e Silveira (2009), ou por meio de dados econométricos, caso de Oliveira e Carvalho (2007).

Em todos os casos, a determinação do custo de oportunidade não é a finalidade em si do artigo, ao contrário deste texto, que procura determinar o valor dessa variável. Além disso, esta pesquisa, ao contrário das citadas, concentra-se na pessoa física comum. 
Já nos estudos internacionais observam-se pesquisas aplicadas à área judicial. Keir e Keir (1983), em seu estudo teórico, discutiram sobre a utilização do custo de oportunidade como a taxa de juros a ser empregada antes do veredito da ação. Segundo os autores, os tribunais devem estar dispostos a ajustar as taxas de juros para refletir as condições do mercado monetário, sendo assim fiéis ao conceito de compensação proporcional completa em relação à perda. Deste modo, a taxa de juros representa o custo de oportunidade que a parte obteria pela aplicação do recurso no mercado monetário.

Lott (1987) empregou o conceito de custo de oportunidade em condenações penais. O autor desenvolveu uma modelagem econométrica que permitiu verificar que indivíduos ricos influenciam o resultado de seus julgamentos por meio da compra de serviços jurídicos, o que pode ser consistente com a literatura penal ideal; no entanto, não aplicou o modelo a dados empíricos.

Lynk (1990) analisou a compensação de advogados, por meio de honorários advocatícios, definidos pela perspectiva das partes e pela justiça. Bebchuk e Guzman (1996) estudaram o papel estratégico no estabelecimento de honorários advocatícios, em que o custo de oportunidade se apresenta como o valor mínimo do contrato firmado entre as partes e o advogado.

Observa-se nesses estudos que a mensuração do custo de oportunidade para pessoas físicas não é a finalidade em si do artigo, ao contrário deste texto, que procura determinar o valor dessa variável. Além disto, Keir e Keir (1983) apresentaram argumentos teóricos que convergem com resultados desta pesquisa, de que a taxa de juros a ser empregada deve ser comparada aos ganhos que poderiam ser obtidos em investimentos no mercado monetário. No entanto, comparações com resultados de pesquisas empíricas similares não serão possíveis, conforme se pode observar pela natureza dos artigos evidenciados, o que representa tanto uma limitação quanto um ponto de destaque deste estudo.

\section{Metodologia}

Para consecução dos objetivos, o trabalho se enquadra como uma pesquisa empírico-teórica, ao analisar o custo de oportunidade do dinheiro em processos judiciais eletrônicos. Com uma abordagem descrita em função da demonstração e análise dos dados processuais, sendo essa análise efetuada por meio de técnicas quantitativas, conforme descritas nos itens abaixo.

\subsection{Da coleta dos dados}

Para o desenvolvimento da pesquisa foi utilizada a totalidade dos processos eletrônicos cadastrados pela PU-GO no período de janeiro de 2007 (mês posterior à publicação da Lei $\mathrm{n}^{\circ}$ 11.419, de 19 de dezembro de 2006) a dezembro de 2010. 
O Sistema Integrado de Controle das Ações (Sicau), empregado pela Advocacia-Geral da União no controle da movimentação de processos judiciais, foi utilizado para emissão de uma listagem contendo dados como: o número de todos os processos eletrônicos ajuizados contra a PU-GO, em Goiás, a parte autora, o tipo de demanda e a data de cadastramento. A data do cadastramento refere-se à data de entrada no sistema da PU-GO.

De posse da listagem, passou-se à consulta individual dos processos no site da Justiça Federal, para coletar informações da conclusão ou não dos trâmites processuais, data de ajuizamento, data da sentença, valores e datas de apresentação dos cálculos da PU-GO, valores pagos por requisição de pequeno valor (RPV) e sua respectiva data de pagamento.

No período delimitado foram consultados 5.365 processos; sendo 1.100 de 2007, 2.117 de 2008, 1.287 de 2009 e 861 de 2010.

Para atingir o objetivo da pesquisa, a análise dos dados recaiu somente nos processos em que a PU-GO apresentou cálculos. Quando ela elabora os cálculos de determinado processo, o autor possui duas alternativas de escolha: aceitar os cálculos ou contestá-los.

Ao optar entre as alternativas de concordar ou contestar os cálculos apresentados pela PU-GO, implica ressaltar que o autor analisará os fluxos de caixa presentes e futuros de sua decisão. A aceitação dos cálculos elaborados pela PU-GO representa o recebimento de um fluxo presente, e a contestação, a expectativa de um fluxo futuro.

A escolha entre uma destas alternativas gera um custo de oportunidade do dinheiro, demonstrado pela figura 2 .

Figura 2

Diferença entre alternativas de escolha para parte autora

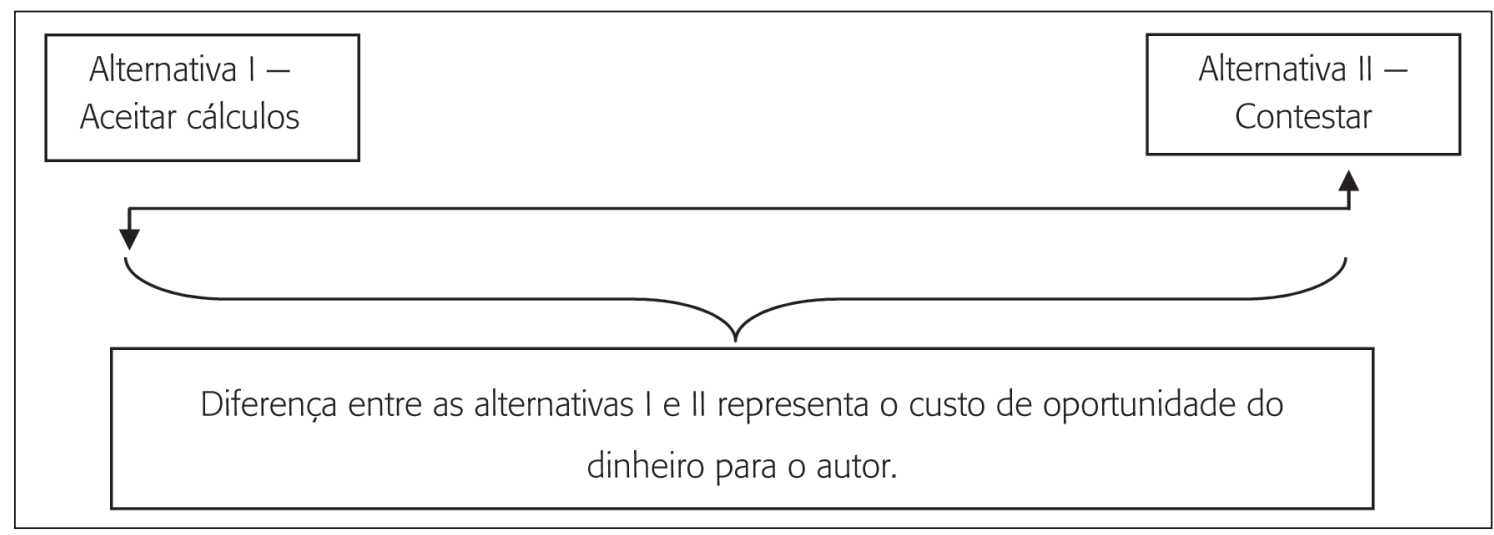

Fonte: Elaborada pelos autores.

Os processos em que a PU-GO apresentou cálculos foram subdivididos pela alternativa de escolha do autor, contestar ou concordar com cálculos da Procuradoria, conforme tabela 1. 
Tabela 1

Processos subdivididos pela alternativa de escolha da parte autora

\begin{tabular}{|lrrrrrr|}
\hline Decisão da Parte Autora & 2007 & 2008 & 2009 & 2010 & \multicolumn{1}{c|}{ Total } & \multicolumn{1}{c|}{$\%$} \\
\hline Concordou & 151 & 221 & 220 & 7 & 599 & $91,59 \%$ \\
Não Concordou & 36 & 16 & 2 & 1 & 55 & $8,41 \%$ \\
Total & 187 & 237 & 222 & 8 & 654 & $100,00 \%$ \\
\hline
\end{tabular}

Fonte: Elaborada pelos autores.

A tabela 1 demonstra que no período de 2007 a 2010 a PU-GO apresentou cálculos para 654 processos, nestes a parte autora concordou com 599, o que representa um percentual de $91,59 \%$ sobre o total de processos, e contestou 55 , o que constitui um percentual de $8,41 \%$ do total. É importante notar que o ano diz respeito à data de entrada do processo no sistema de controle de processos da PU-GO.

Durante a coleta de dados, atualizada até 15 de janeiro de 2011, obtiveram-se apenas oito processos úteis à pesquisa no ano de 2010, e em apenas um deles a parte autora discordou dos cálculos da PU-GO. E por essa limitação, o ano de 2010 será estudado de forma conjunta para todo o período de cálculo, diferentemente dos demais, que serão abordados individualmente, quando do cálculo do custo de oportunidade. O número reduzido de processos para 2010 era esperado já que a maioria dos casos ainda estava em análise.

\subsection{Das técnicas utilizadas para geração dos resultados}

Com os processos já separados segundo a alternativa de escolha do autor, passa-se ao cálculo do custo de oportunidade do dinheiro. Para este estudo, optou-se pelo cálculo da taxa interna de retorno. Esse tipo de mensuração permitirá que a parte autora compare as taxas de retorno interna obtidas com diferentes taxas de retorno em aplicações financeiras, comparando os possíveis retornos com o tempo e risco de sua obtenção.

Serão calculados dois tipos de taxa interna de retorno, a média e a efetiva. Para o cálculo da taxa interna de retorno média (Assaf Neto, 2003), será utilizada a totalidade dos processos eletrônicos estudados, ou seja, independentemente da alternativa de escolha do autor. Enquanto, para o cálculo da taxa de retorno efetiva, serão utilizados apenas os processos em que a parte autora contestou a PU-GO.

\subsubsection{Taxa de retorno média}

Na determinação da taxa de retorno média foram utilizados todos os processos em que a PUGO apresentou cálculos, independentemente da alternativa de escolha da parte autora. Sua 
apuração necessita de cálculos preliminares, como os valores médios recebidos para cada alternativa do autor - concordar e discordar dos valores da PU-GO - e prazos de recebimento. Pelas fórmulas 1 e 2 determinam-se os valores médios recebidos para as alternativas da parte autora:

$$
\begin{aligned}
\bar{X}_{i} & =\left(\frac{\sum_{i=1}^{n} X_{i}}{n_{x}}\right) \\
\bar{Y}_{i} & =\left(\frac{\sum_{i=1}^{n} Y_{i}}{n_{y}}\right)
\end{aligned}
$$

Nas equações 1 e $2, X_{i}$ representa os valores correspondentes à alternativa em que o autor contesta os cálculos apresentados pela PU-GO; $Y_{i}$, os valores para a alternativa em que o autor concorda com os mesmos; e $n$ representa o número de processos para cada alternativa.

O prazo médio de recebimento será o resultado da aplicação da fórmula 3 , em dois momentos distintos. O primeiro, obtido dos processos em que a parte autora concordou com os cálculos da PU-GO, e, o segundo, obtido apenas daqueles em que a parte autora discordou dos valores apresentados pela PU-GO, após a determinação destes será realizada a diferença entre os prazos de recebimento dos processos que o autor concorda e discorda dos cálculos apurados pela PU-GO.

$$
P M R=\frac{\sum(D T r b-D T a j)}{n}
$$

Na equação 3, o prazo médio de recebimento, $P M R$, foi apurado pelo somatório da diferença entre as datas de recebimento efetivo do direito do autor, $D T r b$, e a data em que ele ajuizou a ação, DTaj, início da ação, dividida pela quantidade total de processos.

Com as informações relativas ao prazo médio de recebimento e diferenças médias entre as duas alternativas de escolha, concordância e discordância, será determinada a taxa de retorno média entre as alternativas pela equação 4.

$$
\bar{k}=\sqrt[P M R]{\frac{\bar{X}_{i}}{\bar{Y}_{i}}}-1
$$

Dessa forma, a taxa de retorno média será o custo de oportunidade do dinheiro para a alternativa em que a parte autora concorda/contesta com os cálculos apresentados pela PUGO. Essa taxa será evidenciada de forma mensal. 


\subsubsection{Taxa de retorno efetiva}

Para a taxa de retorno efetiva serão utilizados os processos em que a parte autora contestou os cálculos apresentados pela PU-GO. Sua determinação depende da apuração dos valores médios recebidos pela autora, ao contestar os cálculos da PU-GO, valores médios apurados pela PU-GO e diferença entre os prazos médios de recebimento e apresentação dos cálculos da PU-GO. Os valores médios recebidos e apresentados pela PU-GO são determinados pela aplicação das fórmulas 1 e 5.

$$
\bar{Z}_{i}=\left(\frac{\sum_{i=1}^{n} Z_{i}}{n_{x}}\right)
$$

O valor médio calculado pela PU-GO é apurado pela fórmula 5, em que $Z_{i}$ é o valor do cálculo efetuado pela PU-GO nos processos em que a parte autora os contestou.

O prazo médio de recebimento será obtido pela diferença entre o prazo médio recebido pela parte autora ao discordar dos cálculos da PU-GO e o prazo médio de apresentação dos cálculos, ambos obtidos pela aplicação da fórmula 3 .

Com os dados obtidos passa-se à apuração da taxa de retorno efetiva determinada pela aplicação da fórmula 6:

$$
\bar{k}=\sqrt[P M R]{\frac{\bar{X}_{i}}{\bar{Z}_{i}}}-1
$$

Ao se aplicar os resultados obtidos pelas fórmulas 1, 3 e 5 na de número 6, será auferido o custo de oportunidade do dinheiro para o autor nas alternativas de concordar e contestar os cálculos apresentados pela PU-GO, representada pela PU-GO, nos processos eletrônicos.

\subsubsection{Análise estatística}

Os dados depois de tabulados foram submetidos a testes estatísticos paramétricos e não paramétricos; esses testes se fazem necessários para verificação da existência ou não de igualdade estatística entre as variáveis utilizadas na apuração da taxa de retorno média e efetiva. As variáveis a serem testadas são: valor recebido, valor calculado pela PU-GO e prazo de recebimento; ambos divididos pela alternativa de escolha e gênero da parte autora.

Diferentes estudos enfatizam que homens e mulheres possuem processos de tomada de decisão distintos, em que o gênero feminino é mais conversador, possuindo maior aversão ao risco (Powell e Ansic, 1997; Bajtelsmit e Bernasek, 1996; Jianakoplos e Bernasek, 1998). Portanto, em função de que o processo de tomada de decisão entre o gênero é diferenciado, 
naturalmente, o custo de oportunidade também poderá ser distinto; assim, é necessário segregar os valores e prazos de recebimento por gênero da parte autora.

Como teste paramétrico, será utilizado o teste $t$ para amostras independentes no intuito de verificar se as diferentes médias, por alternativa da parte autora e por gênero, são estatisticamente iguais.

Os testes não paramétricos a serem empregados são os de Mann-Whitney e Kolmogorov-Smirnov. O teste Mann-Whitney é utilizado como alternativa não paramétrica para o teste $t$, para verificação da hipótese de que as duas médias populacionais são iguais. Já o teste Kolmogorov-Smirnov identifica se as variáveis testadas são provenientes de uma mesma distribuição.

\section{Análise dos resultados}

\subsection{Mensuração da taxa de retorno média}

Para o cálculo da taxa de retorno média é necessário apurar os valores médios recebidos pela parte autora ao concordar e ao contestar os cálculos da PU-GO, bem como os prazos médios de recebimento por alternativa de escolha da parte autora e sua respectiva diferença. Para tal, foi utilizada a totalidade de processos em que a PU-GO apresentou cálculos.

A tabela 2 demonstra os valores médios calculados para a alternativa da parte autora.

Tabela 2

Valores obtidos por alternativa de escolha da parte autora

\begin{tabular}{|c|c|c|c|c|c|c|c|c|}
\hline \multirow[b]{2}{*}{ Descrição } & \multicolumn{2}{|c|}{ Ano 2007} & \multicolumn{2}{|c|}{ Ano 2008} & \multicolumn{2}{|c|}{ Ano 2009} & \multicolumn{2}{|c|}{ Período de 2007 a 2010} \\
\hline & $\begin{array}{c}\text { Autor } \\
\text { concorda } \\
\text { com União }\end{array}$ & $\begin{array}{c}\text { Autor } \\
\text { contesta } \\
\text { União }\end{array}$ & $\begin{array}{c}\text { Autor } \\
\text { concorda } \\
\text { com União }\end{array}$ & $\begin{array}{l}\text { Autor } \\
\text { contesta } \\
\text { União }\end{array}$ & $\begin{array}{c}\text { Autor } \\
\text { concorda } \\
\text { com União }\end{array}$ & $\begin{array}{l}\text { Autor } \\
\text { contesta } \\
\text { União }\end{array}$ & $\begin{array}{c}\text { Autor } \\
\text { concorda } \\
\text { com União }\end{array}$ & $\begin{array}{c}\text { Autor } \\
\text { contesta } \\
\text { União }\end{array}$ \\
\hline $\begin{array}{c}\text { Valor médio } \\
\text { recebido }\end{array}$ & $4.920,12$ & $7.492,27$ & $6.377,04$ & $6.487,33$ & $9.879,96$ & $11.311,45$ & $7.362,75$ & $7.311,28$ \\
\hline $\begin{array}{l}\text { Desvio } \\
\text { Padrão }\end{array}$ & $5.204,98$ & $8.870,70$ & $5.388,05$ & $4.519,11$ & $6.813,18$ & $8.591,09$ & $6.259,09$ & $7.674,02$ \\
\hline Mediana & $3.789,46$ & $4.104,68$ & $4.695,52$ & $6.313,44$ & $7.495,65$ & $11.311,45$ & $4.786,70$ & $5.234,38$ \\
\hline Mínimo & 8,15 & 340,36 & 67,53 & 576,77 & 756,33 & $5.236,63$ & 8,15 & 340,36 \\
\hline Máximo & $28.300,00$ & $41.169,92$ & $27.900,00$ & $19.079,95$ & $28.671,10$ & $17.386,26$ & $28.671,10$ & $41.169,92$ \\
\hline $\mathrm{N}$ & 151 & 36 & 221 & 16 & 220 & 2 & 599 & 55 \\
\hline
\end{tabular}

Fonte: Elaborada pelos autores.

Dos dados apresentados na tabela 2, o maior valor médio recebido pela parte autora, ao concordar com os cálculos elaborados pela PU-GO, foi de R\$12.061,78 no ano de 2010, 
enquanto, ao contestar o maior valor médio recebido, foi de $R \$ 11.311 .45$, correspondente ao ano de 2009.

Para todo o período da pesquisa, 2007 a 2010, verificou-se que o menor valor recebido foi de R\$ 8,15, para a parte autora que concordou com os cálculos elaborados pela PU-GO, enquanto o menor valor recebido ao discordar dos cálculos foi de R\$ 340,36.

A comparação dos valores indicados para cada ano da pesquisa permite a inferência de que os valores recebidos pelas partes autoras que contestaram aqueles calculados pela PU-GO são superiores aos valores recebidos pelas partes autoras que concordaram com os cálculos da PU-GO.

No entanto, a análise conjunta do período de pesquisa revelou que, ao contestar, o autor obteve R \$ 7.311,28, como valor médio, enquanto, ao concordar com os cálculos da PUGO, recebeu o valor médio de R\$7.362,75. Portanto, verifica-se que, ao concordar, o autor obteve uma diferença positiva de $\mathrm{R}$ \$ 51,47 em relação ao valor médio obtido pela contestação dos cálculos da PU-GO.

Apesar de isso ocorrer, é importante destacar que os valores medianos das pessoas que contestam são superiores aos valores medianos daqueles que concordam com os cálculos. Tal fato seria um sinal de que alguns montantes recebidos sem contestação estão acima dos valores medianos, podendo ser tratados como outliers. A presença destes nos dados coletados foi o que influenciou o desvio padrão apurado, fazendo-o variar acima da própria média dos valores recebidos ao contestar ou concordar com os cálculos da PU-GO.

Os prazos médios de recebimentos estão evidenciados na tabela 3.

Tabela 3

Prazos médios de recebimento por alternativa de escolha da parte autora

\begin{tabular}{|c|c|c|c|c|c|c|c|c|}
\hline \multirow[b]{2}{*}{ Descrição } & \multicolumn{2}{|c|}{ Ano 2007} & \multicolumn{2}{|c|}{ Ano 2008} & \multicolumn{2}{|c|}{ Ano 2009} & \multicolumn{2}{|c|}{2007 a 2010} \\
\hline & $\begin{array}{c}\text { Autor } \\
\text { concorda } \\
\text { União }\end{array}$ & $\begin{array}{c}\text { Autor } \\
\text { contesta } \\
\text { União }\end{array}$ & $\begin{array}{c}\text { Autor } \\
\text { concorda } \\
\text { União }\end{array}$ & $\begin{array}{c}\text { Autor } \\
\text { contesta } \\
\text { União }\end{array}$ & $\begin{array}{c}\text { Autor } \\
\text { concorda } \\
\text { união }\end{array}$ & $\begin{array}{l}\text { Autor } \\
\text { contesta } \\
\text { União }\end{array}$ & $\begin{array}{l}\text { Autor } \\
\text { concorda } \\
\text { União }\end{array}$ & $\begin{array}{l}\text { Autor } \\
\text { contesta } \\
\text { União }\end{array}$ \\
\hline $\begin{array}{l}\text { Prazo médio de } \\
\text { recebimento }\end{array}$ & 21,73 & 38,28 & 22,07 & 26,56 & 15,24 & 14,50 & 19,39 & 33,58 \\
\hline Diferença & \multicolumn{2}{|c|}{16,55} & \multicolumn{2}{|c|}{4,49} & \multicolumn{2}{|c|}{$-0,74$} & \multicolumn{2}{|c|}{14,19} \\
\hline
\end{tabular}

Fonte: Elaborada pelos autores.

Na tabela 3 observam-se os prazos médios mensais de recebimento para a parte autora por suas alternativas de escolha, bem como a diferença de prazos entre essas alternativas e os prazos mínimos e máximos de recebimento.

Em todo o período da pesquisa, 2007 a 2010, o prazo médio de recebimento dos processos em que a parte autora concordou com os cálculos da PU-GO foi de 19,39 meses, enquanto ao contestar o autor obteve um prazo médio de 33,58 meses. 
A diferença de prazos de recebimento entre as duas alternativas de escolha é de 14,19 meses, indicando que, ao optar por contestar os cálculos apresentados pela PU-GO, a parte autora teve um acréscimo de 14,19 meses no recebimento de seus direitos, para todo período analisado.

Destaca-se, ainda, que o maior prazo médio de recebimento foi no ano de 2007 de 38,28 meses, para a alternativa em que o autor discorda dos cálculos da PU-GO, sendo o menor prazo de recebimento o de 14,50 meses em 2009, relativos aos processos em que o autor discordou dos valores apresentados pela PU-GO.

Para o ano de 2009, verifica-se uma diferença negativa de 0,74 mês pela confrontação dos prazos médios de recebimento para as duas alternativas de escolha do autor. Assim, ao concordar com os cálculos da PU-GO, o autor recebeu seus direitos com um acréscimo de 0,74 mês em relação aos processos dos autores que discordaram dos cálculos da PU-GO.

Observa-se que, com exceção do ano de 2009, o prazo de recebimento de valores para as partes autoras que contestaram os cálculos da PU-GO é superior aos prazos médios de recebimento daqueles que concordaram. Tal fato apresenta a natureza lógica do trâmite de um processo judicial, para o qual uma contestação gerará um reexame dos cálculos elaborados entre parte autora, ré e juiz, o que naturalmente incorrerá em um prazo maior para o recebimento do valor contestado.

É interessante notar que a diferença de prazo apresenta valores reduzidos nos anos recentes. Esse aspecto deve ser considerado com cuidado, já que o número de processos analisados em que ocorreu divergência entre a parte autora e a PU-GO é reduzido: dois em 2009 e um em 2010.

O cálculo do custo de oportunidade pode ser determinado pela taxa de retorno média obtida da diferença entre os prazos médios de recebimentos das alternativas de escolha da parte autora, seja concordar, seja discordar dos cálculos elaborados pela PU-GO. Os resultados estão demonstrados na tabela 4.

Tabela 4

Taxa de retorno média - Diferença de PMR entre as alternativas do autor

\begin{tabular}{|c|c|c|c|c|c|c|c|c|}
\hline \multirow[b]{2}{*}{ Descrição } & \multicolumn{2}{|c|}{2007} & \multicolumn{2}{|c|}{2008} & \multicolumn{2}{|c|}{2009} & \multicolumn{2}{|c|}{2007 a 2010} \\
\hline & Contesta & Concorda & Contesta & Concorda & Contesta & Concorda & Contesta & Concorda \\
\hline $\begin{array}{l}\text { Valor médio } \\
\text { recebido }\end{array}$ & $7.492,27$ & $4.920,12$ & $6.487,33$ & $6.377,04$ & $11.311,45$ & $9.879,96$ & $7.311,28$ & $7.362,75$ \\
\hline $\begin{array}{l}\text { Diferença entre } \\
\text { os PMR }\end{array}$ & \multicolumn{2}{|c|}{16,55} & \multicolumn{2}{|c|}{4,49} & \multicolumn{2}{|c|}{$-0,74$} & \multicolumn{2}{|c|}{14,19} \\
\hline $\begin{array}{l}\text { Taxa de Retorno } \\
\text { Média Mensal }\end{array}$ & \multicolumn{2}{|c|}{$2,57 \%$} & \multicolumn{2}{|c|}{$0,38 \%$} & \multicolumn{2}{|c|}{$-16,79 \%$} & \multicolumn{2}{|c|}{$-0,05 \%$} \\
\hline
\end{tabular}

Fonte: Elaborada pelos autores.

A tabela 4 demonstra os resultados da taxa de retorno média alcançados pela aplicação da diferença entre os prazos médios de recebimento, nas duas alternativas de escolha da parte autora, contestar e concordar com os valores apurados pela PU-GO. 
Assim, em 2007 a parte autora obteve um custo de oportunidade de 2,57\% ao mês. Ao optar pela alternativa de concordar, ela perderia uma taxa de retorno média de $2,57 \%$ e ao discordar ganharia essa taxa mensal.

Para o ano de 2008, a taxa de retorno foi de 0,38\% ao mês, enquanto em 2009 foi uma taxa negativa de 16,79\% ao mês, influenciada tanto pela diferença negativa encontrada entre os prazos médios de recebimento, quanto pela diferença de valores médios recebidos.

A taxa de retorno média, para todo o período de cálculo e utilizando a diferença entre os prazos médios de recebimento nas duas alternativas do autor, foi negativa em 0,05\% ao mês em função de o valor médio recebido na concordância dos cálculos ser maior do que o valor ao discordar da PU-GO.

Portanto, para todo o período da pesquisa, significa dizer que o autor, ao discordar dos cálculos da PU-GO, além de receber um valor menor, acresceu ao recebimento um prazo de 14,19 meses, com uma taxa de retorno negativa em 0,05\% ao mês.

Este resultado não é coerente pelo fato de a comparação não ser uniforme. Afinal, nesse caso, comparam-se processos distintos: alguns em que a parte autora recorreu e outros em que não houve discussão quanto ao valor. Para resolver esse problema, serão analisados, no próximo item, somente os processos em que ocorreu discordância.

\subsection{Mensuração da taxa de retorno efetiva}

Para o cálculo da taxa de retorno efetiva utilizou-se apenas dos processos em que a parte autora discordou dos cálculos elaborados pela PU-GO. Assim, as variáveis usadas no cálculo da taxa de retorno efetiva são: prazo médio de recebimento; prazo médio de apresentação de valores pela PU-GO; valor médio recebido pela parte autora discordar da PU-GO; e valores médios apurados pela PU-GO.

Os valores médios relativos ao recebimento e apresentação de cálculos pela PU-GO estão demonstrados na tabela 5 .

Tabela 5

Valores obtidos dos processos que a parte autora discorda dos cálculos da União

\begin{tabular}{|c|c|c|c|c|c|c|c|c|}
\hline \multirow[b]{2}{*}{ Descrição } & \multicolumn{2}{|c|}{ Ano 2007} & \multicolumn{2}{|c|}{ Ano 2008} & \multicolumn{2}{|c|}{ Ano 2009} & \multicolumn{2}{|c|}{ Período de 2007 a 2010} \\
\hline & $\begin{array}{c}\text { Valor da } \\
\text { União }\end{array}$ & $\begin{array}{l}\text { Valor ao } \\
\text { contestar }\end{array}$ & $\begin{array}{c}\text { Valor da } \\
\text { União }\end{array}$ & $\begin{array}{l}\text { Valor ao } \\
\text { contestar }\end{array}$ & $\begin{array}{c}\text { Valor da } \\
\text { União }\end{array}$ & $\begin{array}{l}\text { Valor ao } \\
\text { contestar }\end{array}$ & $\begin{array}{c}\text { Valor } \\
\text { apurado } \\
\text { pela União }\end{array}$ & $\begin{array}{l}\text { Valor ao } \\
\text { contestar }\end{array}$ \\
\hline $\begin{array}{l}\text { Valor médio } \\
\text { recebido }\end{array}$ & $4.238,16$ & $7.492,27$ & $4.669,87$ & $6.487,33$ & $3.310,37$ & $11.311,45$ & $4.638,17$ & $7.311,28$ \\
\hline Desvio padrão & $8.127,93$ & $8.870,70$ & $4.725,98$ & $4.519,11$ & $1.601,37$ & $8.591,09$ & $7.223,11$ & $7.674,02$ \\
\hline Mediana & $1.283,71$ & $4.104,68$ & $2.859,57$ & $6.313,44$ & $3.310,37$ & $11.311,45$ & $1.751,98$ & $5.234,38$ \\
\hline $\begin{array}{l}\text { Mínimo } \\
\text { recebido }\end{array}$ & - & 340,36 & - & 576,77 & $2.178,03$ & $5.236,63$ & - & 340,36 \\
\hline $\begin{array}{l}\text { Máximo } \\
\text { recebido }\end{array}$ & $41.169,92$ & $41.169,92$ & $19.079,95$ & $19.079,95$ & $4.442,71$ & $17.386,26$ & $41.169,92$ & $41.169,92$ \\
\hline N & & & & & & 2 & & \\
\hline
\end{tabular}

Fonte: Elaborada pelos autores. 
Observa-se na tabela 5, nos anos de 2007 a 2010, que, ao contestar os cálculos da PUGO, o autor recebeu valores médios maiores do que os calculados pela PU-GO (PU-GO). Contudo, como indica o ano de 2010, o valor médio recebido ao contestar os cálculos foi o mesmo valor apresentado pela PU-GO; nesse ano houve apenas um processo cujo autor contestou. Para o ano de 2007, verifica-se que o maior valor recebido pelo autor ao contestar os cálculos foi igual ao maior valor apurado pela PU-GO.

Percebe-se que o valor médio recebido pela parte autora, durante todo o período da pesquisa, 2007 a 2010, ao contestar os cálculos apresentados pela PU-GO, representa uma diferença, a maior de $\mathrm{R} \$ 2.673,11$, sobre aqueles apurados pela PU-GO.

Pela análise dos valores absolutos na tabela 5, quando confrontados os valores calculados com os contestados, os valores da PU-GO estão abaixo dos cálculos elaborados na contestação. Os valores apresentados na contestação podem ser analisados como a expectativa da parte autora; assim, uma vez que os valores apresentados pela PU-GO estão abaixo das expectativas de recebimento da parte autora, ela incorrerá no custo de contestar os cálculos da PU-GO.

Frisa-se que a decisão de quais valores o autor irá receber é do juiz. Este analisará todas as opções de cálculo e decidirá qual a que melhor reflete as determinações contidas nos autos processuais.

O desvio padrão calculado e demonstrado na tabela 5 foi influenciado por outliers. Uma evidência da presença desses dados discrepantes são os valores mínimos e máximos encontrados de $\mathrm{R} \$ 0,00$ e $\mathrm{R} \$ 41.169,92$, respectivamente. E, segundo os valores apresentados, os desvios diferem de forma demasiada dos apurados como valores médios e medianos.

Os prazos médios de recebimento da parte autora ao contestar os cálculos da PU-GO, bem como os prazos de apresentação dos cálculos, estão evidenciados na tabela 6. Observa-se, nessa tabela, que o maior prazo médio de recebimento pelo autor ao contestar foi de 38,28 meses para o ano de 2007, enquanto o menor prazo de recebimento foi de 14,50 meses em 2009.

Tabela 6

Prazos médios de recebimento ao contestar e prazos médios de apresentação de cálculos

\begin{tabular}{|c|c|c|c|c|c|c|c|c|}
\hline \multirow[b]{2}{*}{ Descrição } & \multicolumn{2}{|c|}{ Ano 2007} & \multicolumn{2}{|c|}{ Ano 2008} & \multicolumn{2}{|c|}{ Ano 2009} & \multicolumn{2}{|c|}{2007 a 2010} \\
\hline & $\begin{array}{c}\text { União } \\
\text { apresenta } \\
\text { cálculos }\end{array}$ & $\begin{array}{c}\text { Autor } \\
\text { Contesta }\end{array}$ & $\begin{array}{c}\text { União } \\
\text { apresenta } \\
\text { cálculos }\end{array}$ & $\begin{array}{c}\text { Autor } \\
\text { Contesta }\end{array}$ & $\begin{array}{c}\text { União } \\
\text { apresenta } \\
\text { cálculos }\end{array}$ & $\begin{array}{c}\text { Autor } \\
\text { Contesta }\end{array}$ & $\begin{array}{c}\text { União } \\
\text { apresenta } \\
\text { cálculos }\end{array}$ & $\begin{array}{c}\text { Autor } \\
\text { Contesta }\end{array}$ \\
\hline Prazos médios & 21,11 & 38,28 & 16,94 & 26,56 & 8,50 & 14,50 & 19,27 & 33,58 \\
\hline \multicolumn{9}{|l|}{ Diferença entre } \\
\hline os prazos & \multicolumn{2}{|c|}{17,17} & \multicolumn{2}{|c|}{9,63} & \multicolumn{2}{|c|}{6,00} & \multicolumn{2}{|c|}{14,31} \\
\hline
\end{tabular}

Fonte: Elaborada pelos autores.

Novamente, pode-se perceber que a inclusão de uma contestação dos cálculos da PUGO naturalmente aumentará o prazo médio de recebimento, tendo em vista que o reexame 
dos cálculos gerará prazos de análise tanto para a parte autora (elaboração dos novos cálculos) quanto para a PU-GO (análise dos novos cálculos) e para o juiz que definirá sobre quais cálculos seguem melhor as determinações judiciais contidas no processo.

Com os dados referentes aos prazos médios de recebimento para as duas alternativas de escolha da parte autora, bem como os valores médios recebidos e valores médios apurados pela PU-GO, passa-se ao cálculo da taxa de retorno efetiva.

Com a aplicação da diferença entre os prazos médios de recebimento e apresentação de cálculos pela PU-GO, dos processos em que a alternativa de escolha do autor foi a contestação de cálculos, encontraram-se os resultados evidenciados na tabela 7.

Tabela 7

Taxa de retorno efetiva - diferença entre os prazos

\begin{tabular}{|c|c|c|c|c|c|c|c|c|}
\hline \multirow[b]{2}{*}{ Descrição } & \multicolumn{2}{|c|}{2007} & \multicolumn{2}{|c|}{2008} & \multicolumn{2}{|c|}{2009} & \multicolumn{2}{|c|}{2007 a 2010} \\
\hline & Contesta & União & Contesta & União & Contesta & União & Contesta & União \\
\hline Valor médio recebido & $7.492,27$ & $4.238,16$ & $6.487,33$ & $4.669,87$ & $11.311,45$ & $3.310,37$ & $7.311,28$ & $4.638,17$ \\
\hline Diferença entre os & \multirow{2}{*}{\multicolumn{2}{|c|}{17,17}} & & & & & & \\
\hline prazos & & & \multicolumn{2}{|c|}{9,62} & \multicolumn{2}{|c|}{6,00} & \multicolumn{2}{|c|}{14,31} \\
\hline $\begin{array}{l}\text { Taxa de retorno } \\
\text { efetiva mensal }\end{array}$ & \multicolumn{2}{|c|}{$3,37 \%$} & \multicolumn{2}{|c|}{$3,48 \%$} & \multicolumn{2}{|c|}{$22,73 \%$} & \multicolumn{2}{|c|}{$3,23 \%$} \\
\hline
\end{tabular}

Fonte: Elaborada pelos autores.

O custo de oportunidade do dinheiro, neste âmbito definido como a taxa de retorno efetiva, foi determinado pelo emprego da diferença entre os prazos médios de recebimento e apresentação de cálculos pela PU-GO.

Observa-se, na tabela 7, que para o ano de 2007 a parte autora, ao contestar os cálculos da PU-GO, obteve uma taxa de retorno efetiva de 3,37\% ao mês; gerando um acréscimo no prazo de recebimento de 17,17 meses a mais do que aqueles que concordaram com os cálculos da PU-GO e receberam seus valores imediatamente.

Em 2008, a taxa de retorno efetiva foi de 3,48\% ao mês. Em 2009, a taxa apurada foi de $22,73 \%$ ao mês. Neste ano duas peculiaridades foram observadas; a primeira, a diferença entre prazos de seis meses, a menor do período estudado, e a segunda, a diferença de R\$ 8.001,08 entre os valores médios recebidos e calculados para a parte autora, ao contribuir para a elevação da taxa de retorno efetiva.

Ao utilizar todo o período de cálculo obteve-se uma taxa de retorno efetiva de $3,23 \%$ ao mês, indicando que a parte autora, ao contestar os cálculos da PU-GO, teve um ganho representado pela taxa de retorno efetiva de 3,23\% ao mês, contudo, ao renunciar ao recebimento imediato de valores, postergando-o em 14,31 meses.

Portanto, com a utilização dos processos em que as partes autoras contestaram os cálculos da PU-GO, observa-se que a taxa interna de retorno foi positiva para todos os anos analisados. Assim, verifica-se que, ao contestar as partes autoras, em média, conseguiram aumentar 
o custo de oportunidade, ao escolher, portanto, a melhor alternativa disponível, contestar os cálculos da PU-GO.

\subsection{Análise estatística paramétrica e não paramétrica}

Para os dados coletados na pesquisa, no período de 2007 a 2010, foram aplicados testes estatísticos paramétricos e não paramétricos com a utilização do software estatístico SPSS Statistical Package for the Social Science.

\subsubsection{Teste paramétrico}

Para os dados coletados foi empregado o teste $t$ com o intuito de se verificar se as médias populacionais de amostras são estatisticamente iguais. A análise foi realizada para os dados agrupados por alternativa de escolha e gênero da parte autora, cujos resultados estão demonstrados na tabela 8 .

Tabela 8

Valor médio recebido versus alternativa de escolha do autor

\begin{tabular}{|lrrrr|}
\hline \multicolumn{1}{c}{ Descrição } & \multicolumn{2}{c}{ Médias } & & $\begin{array}{c}\text { Igualdade de variâncias assumidas } \\
\text { Igualdade de variâncias não assumidas }\end{array}$ \\
\cline { 2 - 3 } & Concorda & Contesta & & Sig. (2-caudal) \\
\hline 1. Valor calculado pela PU-GO & $7.355,63$ & $4.471,43$ & 0,001 & - \\
2. Valor recebido & $7.362,75$ & $7.311,28$ & 0,954 & - \\
3. Prazo de recebimento & 19,38 & 33,67 & - & 0,000 \\
\hline
\end{tabular}

Fonte: Elaborada pelos autores.

Em função de a escolha da parte autora ser subsidiada, inicialmente, dos valores apresentados pela PU-GO, decidiu-se verificar se os valores médios calculados pela PU-GO possuem igualdade estatística ao do valor médio recebido pelo autor, cujos resultados estão evidenciados no item 1 da tabela 8.

Examina-se pela significância de 0,001 que os valores médios calculados pela PU-GO são estatisticamente diferentes para cada alternativa da parte autora. É interessante observar que os valores médios calculados para as partes que concordaram com os cálculos da PU-GO são superiores aos valores médios daqueles que discordaram dos cálculos.

O item 2 da tabela apresenta os resultados dos valores recebidos em função da alternativa escolhida pela parte autora. Segundo os dados apresentados para igualdade de variâncias assumidas, o valor médio recebido entre as duas alternativas de escolha da parte autora são estatisticamente iguais, dada a significância encontrada de 0,954. Esse resultado 
precisa ser considerado com certa ressalva; já que os valores correspondem a momentos distintos no tempo.

Ao aplicar o teste $t$ para o prazo de recebimento entre as alternativas de escolha da parte autora, chegou-se aos resultados demonstrados no item 3 da tabela 8. Verifica-se que as variâncias entre as amostras não são iguais, em função da significância encontrada de 0,000. Dessa forma, constatou-se que o prazo médio de recebimento obtido dos processos em que o autor discorda dos cálculos da PU-GO é estatisticamente superior ao prazo médio de recebimento em que a parte autora concorda com os cálculos.

Ao analisar conjuntamente os itens 1, 2 e 3 da tabela 8, percebe-se que os valores médios para a parte autora que contesta os cálculos da União se aproximam da média daqueles que concordaram após a contestação. Assim, pode-se inferir que o valor médio recebido pelos que concordaram com os cálculos representa a expectativa de recebimento das partes autoras, e quando os cálculos da PU-GO não alcançam essa expectativa, a parte autora os contestará, arcando com um prazo maior para recebimento na intenção de que o resultado de sua contestação se aproxime do valor pretendido por ela.

A tabela 9 contém os resultados obtidos por gênero da parte autora, masculino e feminino. Ressalta-se que o gênero das partes autoras foi analisado em função da existência de estudos que argumentam que o processo de tomada de decisão entre homens e mulheres é distinto (Bajtelsmit e Bernasek, 1996; Powell e Ansic, 1997; Jianakoplos e Bernasek, 1998).

Tabela 9

Valor médio recebido versus gênero do autor

\begin{tabular}{|c|c|c|c|c|}
\hline \multirow{3}{*}{ Descrição } & \multicolumn{2}{|c|}{ Médias } & \multirow{2}{*}{$\begin{array}{l}\text { Igualdade de } \\
\text { variâncias assumidas }\end{array}$} & \multirow{2}{*}{$\begin{array}{c}\text { Igualdade de variâncias } \\
\text { não assumidas }\end{array}$} \\
\hline & \multirow{2}{*}{ Feminino } & \multirow{2}{*}{ Masculino } & & \\
\hline & & & \multicolumn{2}{|c|}{ Sig. (2-caudal) } \\
\hline 1. Valor calculado pela PU-GO & $6.784,80$ & $7.475,13$ & - & 0,173 \\
\hline 2. Valor recebido & $6.830,06$ & $7.941,15$ & - & 0,028 \\
\hline 3. Prazo de recebimento & 18,90 & 22,44 & - & 0,000 \\
\hline
\end{tabular}

Fonte: Elaborada pelos autores.

O item 1 da tabela 9 indica que o valor médio calculado para a parte autora com gênero masculino e para o gênero feminino é estatisticamente igual, pela significância de 0,173. Assim, infere-se que a PU-GO não faz distinção em relação ao gênero das partes quando da elaboração dos cálculos.

Para os valores recebidos pelas partes autoras, observou-se no item 2 que as médias dos valores recebidos pelos gêneros masculinos e femininos são estatisticamente desiguais, visto a significância apurada de 0,028. Portanto, estatisticamente, o valor médio recebido pelo gênero feminino é diferente, neste caso menor, do que o recebido pelo masculino. 
Ao prosseguir a análise, executou-se o teste de igualdade de médias para as variáveis de prazo de recebimento e gêneros da parte autora, feminino ou masculino, cujos resultados estão demonstrados no item 3.

Os resultados do item 3 indicam que os prazos de recebimento para os gêneros masculino e feminino possuem diferença estatística, dado o p-valor encontrado de 0,000. Assim, o prazo médio de recebimento do gênero masculino é superior ao feminino. Isso indica que homens e mulheres tomam suas decisões de formas distintas. O gênero feminino parece ser mais conservador do que o masculino, ao optar por um valor menor e com um prazo de recebimento menor.

Outra informação relevante é que, dentre os 55 processos judiciais em que a parte autora contestou os cálculos da PU-GO, 69,09\% foram apresentados pelo gênero masculino. Esses achados corroboram a pesquisa de Powell e Ansic (1997) e Jianokoplos e Bernasek (1998), que encontraram evidências de que homens e mulheres adotam diferentes estratégias de tomada de decisão financeira, em que as mulheres possuem uma menor preferência ao risco, pois têm um maior desejo de segurança, enquanto os homens preferem aumentar os riscos em face de seu desejo por maiores retornos.

\subsubsection{Testes não paramétricos - Mann-Whitney e Kolmogorov-Smirnov}

Os resultados alcançados na aplicação do teste de Mann-Whitney e Kolmogorov-Smirnov entre as variáveis estudadas - valor recebido, prazo de recebimento, valor calculado pela PUGO, alternativa de escolha e gênero da parte autora — podem ser verificados na tabela 10 .

Tabela 10

Teste Mann-Whitney e Kolmogorov-Smirnov

\begin{tabular}{|c|c|c|c|c|c|}
\hline \multirow[b]{2}{*}{ Descrição } & \multicolumn{3}{|c|}{ Mann-Whitney } & \multicolumn{2}{|c|}{ Kolmogorov-Smirnov } \\
\hline & $\begin{array}{c}\text { Mann- } \\
\text { Whitney U }\end{array}$ & Z & Sig. & Z & $\begin{array}{c}\text { Sig. } \\
\text { (2-caudal) }\end{array}$ \\
\hline 1. Valor calculado pela PU-GO e alternativa do autor & 8731,500 & $-5,773$ & 0,000 & 3,652 & 0,000 \\
\hline 2. Valor recebido e alternativa do autor & 15260,000 & $-0,904$ & 0,366 & 1,422 & 0,035 \\
\hline 3. Prazo de recebimento e alternativa do autor & 5949,500 & $-7,856$ & 0,000 & 3,983 & 0,000 \\
\hline 4. Valor calculado pela PU-GO e gênero da parte autora & 52071,000 & $-0,524$ & 0,600 & 1,021 & 0,248 \\
\hline 5. Valor recebido e gênero da parte autora & 51586,000 & $-0,725$ & 0,468 & 1,151 & 0,141 \\
\hline 6. Prazo de recebimento e gênero da parte autora & 43205,000 & $-4,204$ & 0,000 & 2,147 & 0,000 \\
\hline
\end{tabular}

Fonte: Elaborada pelos autores.

Pelo teste Mann-Whitney percebe-se que tanto os valores médios calculados pela PUGO, quanto o prazo médio de recebimento são estatisticamente significantes, dado o p-valor 
encontrado de 0,000. Já os valores médios recebidos pela parte autora que concorda com os cálculos da PU-GO são estatisticamente iguais aos valores médios recebidos pela parte que contesta os cálculos.

Os resultados obtidos com o teste Mann-Whitney ainda demonstraram que os valores médios calculados pela PU-GO para o gênero feminino e masculino, item 4, são estatisticamente iguais, dadas a estatística Z de -0,524 e significância de 0,600.

No item 5 , valor recebido e gênero da parte autora, a significância apurada de 0,468 indicou que o valor médio recebido pelos gêneros masculino e feminino é estatisticamente igual. Esse resultado divergiu do encontrado na aplicação do teste paramétrico em que os valores recebidos por gênero da parte autora são estatisticamente diferentes.

Portanto, faz-se necessário analisar o tipo de distribuição dos dados. O teste de Kolmogorov-Smirnov aponta que distribuições de frequência possuem a mesma distribuição, ou seja, uma distribuição normal, assim o teste mais adequado é o paramétrico - teste $t$.

No item 6 constata-se, pela significância de 0,000 , que o prazo médio de recebimento para o autor de gênero masculino é estatisticamente diferente do prazo médio para o gênero feminino.

Os resultados dos testes não paramétricos confirmaram aqueles encontrados com a aplicação de testes de média paramétricos. Com exceção do item 5, que trata do valor médio recebido pelos gêneros, em que para o teste de Mann-Whitney esses valores não possuem significância estatística.

\section{Considerações finais}

O objetivo do trabalho foi mensurar o custo de oportunidade para a parte autora em processos judiciais eletrônicos, quando da apresentação de cálculos pela PU-GO, o qual foi realizado através da determinação das taxas de retorno médias e efetivas.

Observou-se que a parte autora, ao contestar os cálculos da PU-GO, obteve um ganho, evidenciado pela taxa de retorno efetiva, contudo, com um recebimento tardio de valores. Já a taxa de retorno média, apurada para todo o período de pesquisa, foi negativa, não proporcionando ganho à parte autora, mas apenas o recebimento tardio dos valores apurados pela PU-GO.

Pelos dados e testes estatísticos aplicados, pode-se inferir que a média de valores recebidos pela parte autora, ao concordar com os cálculos da PU-GO, se aproxima dos valores médios recebidos na contestação dos cálculos. Enquanto nos processos em que a parte autora discordou, os valores médios apurados pela PU-GO estão abaixo da média recebida pela parte autora dos processos em que ela concordou com os cálculos.

A contestação dos valores calculados pela PU-GO permitiu que o valor médio recebido pela parte autora se aproximasse da média dos valores recebidos nos processos em que a parte autora concordou com os cálculos da PU-GO. Portanto, quando o valor apresentado está 
abaixo da média recebida, uma contestação poderá ajudá-los a se aproximar do valor médio recebido por aqueles que concordaram os cálculos da PU-GO.

Como complementação da análise dos resultados, segregou-se a parte autora segundo o gênero. Os resultados indicaram que os gêneros masculino e feminino tomam decisões de modos distintos, em que o gênero feminino adota uma postura mais conservadora que o masculino; esses resultados permitiram corroborar com as pesquisas de Powell e Ansic (1997) e Jianokoplos e Bernasek (1998).

A decisão de concordar ou contestar os cálculos deverá ser tomada juntamente com a análise do prazo médio de recebimento e o confronto entre o custo de oportunidade e a taxa de retorno de investimentos no mercado (Keir e Keir, 1983).

O trabalho é relevante por evidenciar, numa situação prática, o custo de oportunidade. Nesse caso, de uma forma geral, o custo obtido encontra-se num valor acima das taxas de riscos usualmente praticadas no Brasil, mostrando que, sob certas circunstâncias, o custo de oportunidade do dinheiro é razoavelmente elevado.

Outro fato importante é que provavelmente a decisão de recorrer depende do prazo de retorno. Um processo que conduza maior celeridade nos processos judiciais poderá acarretar, pelo menos no curto prazo, aumento no número de recursos. Entretanto, essa conclusão não foi possível ser comprovada em razão do horizonte de tempo reduzido da pesquisa.

Por fim, ressalta-se a necessidade da realização de pesquisas direcionadas ao tema custo de oportunidade em processos judiciais. Sugere-se como objeto de estudo os processos judiciais de maior complexidade, que adentram décadas para sua finalização no Poder Judiciário, o que possibilitaria, aos autores desses processos, identificar a melhor alternativa de escolha para sua decisão.

\section{Referências}

ASSAF NETO, Alexandre. Finanças corporativas e valor. São Paulo: Atlas, 2003.

BAJTELSMIT, Vickie L.; BERNASEK, Alexandra. Why do women invest differently than men? Financial counseling and planning. SSRN. 1996. Disponível em: <http://ssrn.com/abstract=2238>. Acesso em: 16 abr. 2010.

BASSO, Fernando C. Opportunity cost: critique of a concept. SSRN. 2005. Disponível em: < http:// papers.ssrn.com/sol3/papers.cfm?abstract_id=868631>. Acesso em: 16 abr. 2010.

BEBCHUK, Lucian A.; GUZMAN, Andrew T. How would you like to pay for that? The strategic effects of fee arrangements on settlement terms. Harvard Negotiation Law Review, v. 1, n. 53, p. 53-63, 1996.

BECKER, Gary S. Crime and punishment: an economic approach. Journal of Political Economy, v. 76, n. 2, p. 169-217, 1968.

BEUREN, Ilse M. Conceituação e contabilização do custo de oportunidade. Caderno de Estudos, Fipecafi, n. 8, p. 1-12, 1993. 
BRASIL. Advocacia-Geral da PU-GO. Funções institucionais. Disponível em: <www.agu.gov.br/ sistemas/site/PaginasInternas/Institucional/func_inst.aspx>. Acesso em: 16 abr. 2010.

BRASIL. Lei n. 5.869, de 11 de janeiro de 1973. Institui o Código de Processo Civil. Disponível em: <www.planalto.gov.br/ccivil/leis/L5869.htm>. Acesso em: 12 dez. 2010.

BRASIL. Lei n. 10.259, de 12 de julho de 2001. Dispõe sobre a instituição dos Juizados Especiais Cíveis e Criminais no âmbito da Justiça Federal. Disponível em: <www.planalto.gov.br/ccivil/Leis/ LEIS_2001/L10259.htm>. Acesso em: 16 abr. 2010.

BRASIL. Lei n. 11.419, de 19 de dezembro de 2003. Dispõe sobre a informatização do processo judicial. Disponível em: < hwww.planalto.gov.br/ccivil_03/_ato2004-2006/2006/lei/111419.htm>. Acesso em: 16 abr. 2010.

BREALEY, Richard; MEYERS, Stewart. Principles of corporate finance. 7. ed. Nova York: McGrawHill, 2003.

BUCHANAN, James M. Cost and choice: an inquiry in economic theory. Chicago: University of Chicago Press, 1969.

CALABRESI, Guido. Some thougths on risk distribution and the law of torts. The Yale Law Journal, v. 70, n. 4, p. 499-553, 1961.

COASE, Ronald H. The problem of social cost. Journal of law and economics, 1960. Disponível em: <www.sfu.ca/ allen/CoaseJLE1960.pdf>. Acesso em: 16 abr. 2010.

FIGUEIREDO, Adelson M. et al. Integração na criação de frangos de corte na microrregião de Viçosa - MG: viabilidade econômica e análise de risco. Revista de Economia e Sociologia Rural, v. 44, n. 4, p. 713-730, 2006.

GONÇALVES, Everton N.; STELZER, Joana. O direito e a law and economics: possibilidade interdisciplinar na contemporânea análise econômico-jurídica internacional. Anais do XV Encontro Preparatório para o Congresso Nacional do Conpedi. Florianópolis: Fundação Boiteux, 2006. Disponível em: <www. geodireito.com/_admDireito/Modbiblioteca/Arquivos/direito_intern_everton_goncalves_e_joana_stelzer.pdf >. Acesso em: 16 abr. 2010.

HEYMANN, Hans G.; BLOOM, Robert. Opportunity cost in finance and accounting. Westport, CT: Quorum Books, 1990.

JIANAKOPLOS, Nancy A.; BERNASEK, Alexandra. Are women more risk averse? Economic Inquiry, v. 36, n. 4, p. 620-630, out. 1998.

KEIR, John C.; KEIR, Robin C. Opportunity cost: a measure of prejudgment interest. The Business Lawyer, v. 39, p. 129-152, 1983.

LOTT, John R. Should the wealthy be able to "buy justice"? Journal of Political Economy, v. 95, n. 6, p. 1307-1316, 1987.

LYNK, William J. The courts and the market an economic analysis of contingent fees in class-action litigation. Journal of Legal Studies, v. 19, p. 247-260, 1990. 
NASCIMENTO, Auster M. Uma contribuição para o estudo dos custos de oportunidade. Dissertação (Mestrado em Controladoria e Contabilidade) - Curso de Pós-Graduação em Controladoria e Contabilidade, Faculdade de Economia, Administração e Contabilidade, Universidade de São Paulo, São Paulo, 1998.

OLIVEIRA, Guilino; CARVALHO, Carlos. O componente "custo de oportunidade" do spread bancário no Brasil: uma abordagem pós-keynesiana. Economia e Sociedade, Campinas, v. 16, n. 3, p. 371-404, 2007.

PARISI, Francesco; ROWLEY, Charles K. The origins of law and economics: essays by the founding fathers. Massachusetts: Edward Elgar Publishing Inc, 2005.

PEREIRA, Anísio C. et al. Custo de oportunidade: conceitos e contabilização. Caderno de Estudos, Fipecafi, n. 2, p. 1-22, 1990.

POSNER, Richard A. Economic analysis of law. 7. ed. Chicago: Aspen Publishers, 2007.

POSNER, Richard A. The economics of Justice. Cambridge: Harvard University Press, 1981.

POWELL, Melanie; ANSIC, David. Gender differences in risk behaviour in financial decision-making: an experimental analysis. Journal of Economic Psychology, v. 18, p. 605-428, 1997.

SALAMA, Bruno M. Direito, justiça e eficiência: a perspectiva de Richard Posner. Fundação Getulio Vargas. Direito GV, São Paulo. ago. 2008. Disponível em: < http://works.bepress.com/bruno_ meyerhof_salama/30>. Acesso em: 30 out. 2010.

SCARPEL, Rodrigo A.; MILIONI, Armando. Utilização conjunta de modelagem econométrica e otimização em decisões de concessão de crédito. Pesquisa Operacional, v. 22, n. 1, p. 61-72, 2002.

VIANA, João G. A.; SILVEIRA, Vicente C. P. Análise econômica da ovinocultura: estudo de caso na Metade Sul do Rio Grande do Sul, Brasil. Ciência Rural, Santa Maria, v. 39, n. 4, p. 1187-1192, 2009.

Michele Rílany Rodrigues Machado é doutoranda em administração pela Universidade de Brasília (UnB) e professora assistente da Universidade Federal de Goiás (UFG). E-mail: michelerilany@gmail.com.

César Augusto Tibúrcio Silva é doutor em controladoria e contabilidade pela Universidade de São Paulo (USP) e professor titular da Universidade de Brasília (UnB). E-mail: cesaraugustotiburciosilva@gmail. com.

Lúcio de Souza Machado é doutorando em psicologia pela Pontifícia Universidade Católica de Goiás (PUC-Goiás) e professor assistente da Universidade Federal de Goiás (UFG).E-mail: lucio@florestaauditores.com.br. 